\title{
The Polycystic Kidney Disease 1 Gene Encodes a 14 kb Transcript and Lies within a Duplicated Region on Chromosome 16
}

\author{
The European Polycystic Kidney Disease \\ Consortium*
}

\section{Summary}

Autosomal dominant polycystic kidney disease (ADPKD) is a common genetic disorder that frequently results in renal failure due to progressive cyst development. The major locus, PKD1, maps to 16p13.3. We identified a chromosome translocation associated with ADPKD that disrupts a gene (PBP) encoding a 14 kb transcript in the PKD1 candidate region. Further mutations of the PBP gene were found in PKD1 patients, two deletions (one a de novo event) and a splicing defect, confirming that PBP is the PKD1 gene. This gene is located adjacent to the TSC2 locus in a genomic region that is relterated more proximally on 16p. The duplicate area encodes three transcripts substantially homologous to the PKD1 transcript. Partial sequence analysis of the PKD1 transcript shows that it encodes a novel protein whose function is at present unknown.

\section{Introduction}

A landmark study by Dalgaard (1957) showed that autosomal dominant polycystic kidney disease (ADPKD), also termed adult polycystic kidney disease, is one of the most common genetic diseases in humans (approximately 1 in 1000 individuals affected). The major feature of this disease is the development of cystic kidneys that commonly leads to renal failure in adult life. This simple description, however, belies the diverse clinical phenotype of ADPKD, which is now considered a systemic disorder (reviewed by Gabow, 1990) and one that occasionally presents in childhood (Fink et al., 1993; Zerres et al., 1993). Extrarenal manifestations include liver cysts (Milutinovic et al., 1980) and (more rarely) cysts of the pancreas (Gabow, 1993) and other organs. Intracranial aneurysms occur in approximately $5 \%$ of patients and are a significant cause of morbidity and mortality due to subarachnoid hemorrhage (Chapman et al., 1992). More recently, an increased prevalence of cardiac valve defects (Hossack et al., 1988), herniae (Gabow, 1990), and colonic diverticulae (Scheff et al., 1980) has been reported.

The major cause of morbidity in ADPKD, however, is progressive renal disease characterized by the formation and enlargement of fluid-filled cysts, resulting in grossly enlarged kidneys. Renal function deteriorates as normal tissue is compromised by cystic growth, resulting in end stage renal disease (ESRD) in more than $50 \%$ of patients by the age of 60 years (Gabow et al., 1992): ADPKD accounts for $8 \%-10 \%$ of all renal transplantation and dialysis patients in Europe and the United States (Gabow, 1993). Biochemical studies have suggested several potential causes of cyst formation and development, including abnormal epithelial cell growth, alterations to the extracel-

\author{
The European Polycystic KIdney Disease \\ Consortium is comprised of the following \\ groups: \\ Group 1: \\ Christopher J. Ward, Belén Peral, Jim Hughes, \\ Sandra Thomas, Vicki Gamble, Angela B. MacCarthy, \\ Jackie Sloane-Stanley, Veronica J. Buckle, \\ Lyndal Kearney, Douglas R. Higgs, Peter J. Ratcliffe, \\ and Peter C. Harris $†$ \\ Medical Research Council Molecular Haematology Unit \\ Institute of Molecular Medicine \\ John Radcliffe Hospital \\ Headington, Oxford OX3 9DU \\ England \\ Group 2: \\ Jeroen H. Roelfsema, Lia Spruit, Jasper J. Saris, \\ Hans G. Dauwerse, Dorien J. M. Peters, \\ and Martijn H. Breuning \\ Department of Human Genetics \\ Leiden University \\ 2333 AL Leiden \\ The Netherlands
}

tCorrespondence should be addressed to Peter C. Harris.

\section{Group 3:}

Mark Nellist,' Phillip T. Brook-Carter,'

Magitha M. Maheshwar, ${ }^{1}$ Isabel Cordeiro, ${ }^{2}$

Heloisa Santos, ${ }^{2}$ Pedro Cabral, ${ }^{3}$

and Julian R. Sampson'

IInstitute of Medical Genetics

University of Wales College of Medicine

Cardiff CF4 4XN

Wales

${ }^{2}$ Genetics Unit

Hospital Santa Maria

${ }^{3}$ Department of Neurology

Hospital D. Estefânia

1699 Lisbon

Portugal

Group 4:

Bart Janssen, Arjenne L. W. Hesseling-Janssen,

Ans M. W. van den Ouweland, Bert Eussen,

Senno Verhoef, Dick Lindhout,

and Dicky J. J. Halley

Department of Clinical Genetics

Erasmus University

and University Hospital

3015 GE Rotterdam

The Netherlands 
a

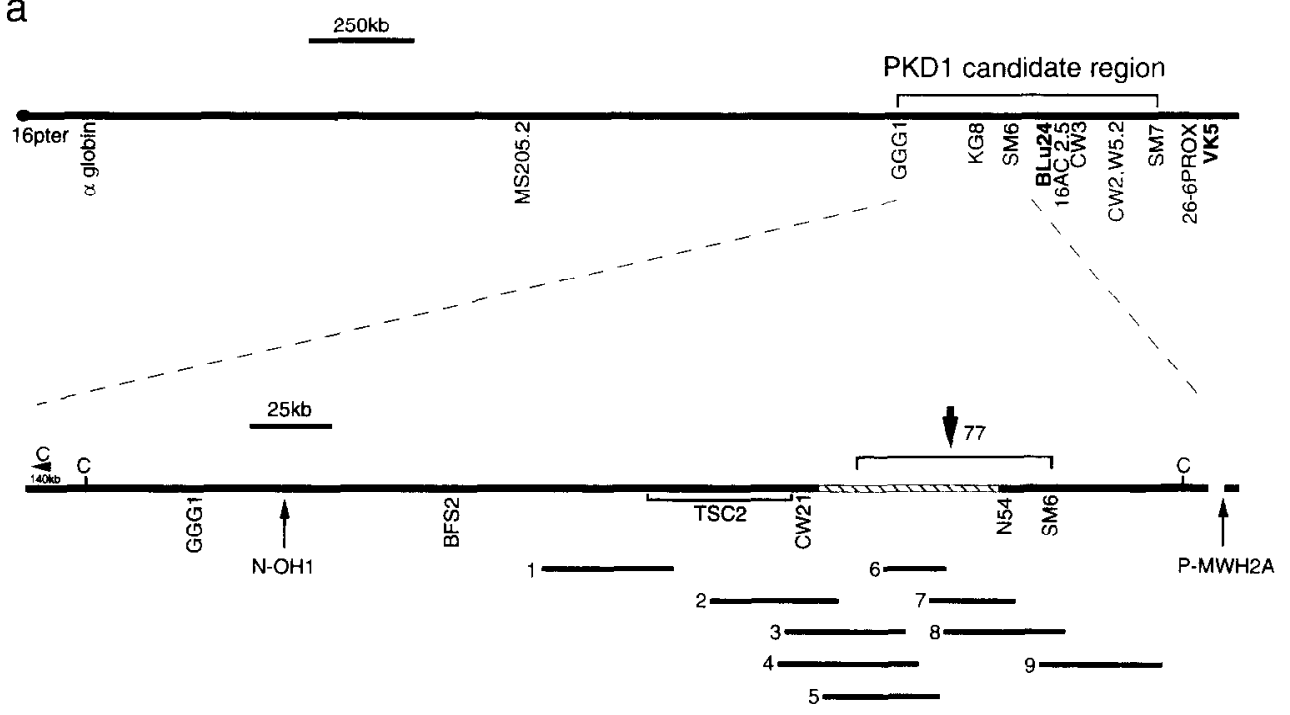

b

C

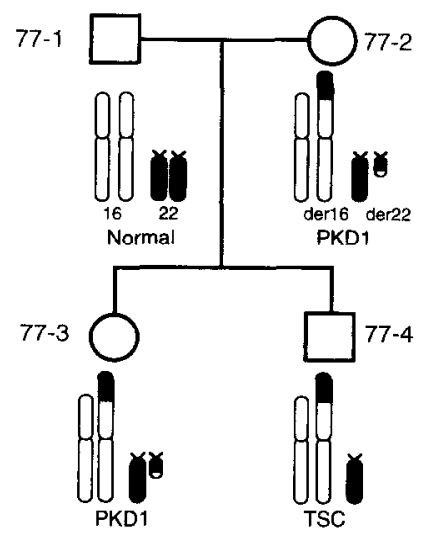

SM6

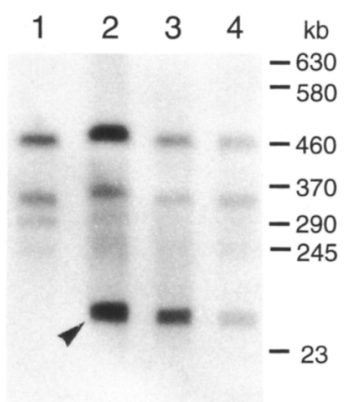

Figure 1. A Chromosome Transiocation Associated with PKD1

(a) (Top) A long-range map of the terminal region of the short arm of chromosome 16 showing the PKD1 candidate region defined by genetic linkage analysis. The positions of selected DNA probes and microsatellites used for haplotype, linkage, or heterozygosity analysis are indicated. Markers previously described in linkage disequilibrium studies are shown in bold (adapted from Harris et al., 1990, 1991; Germino et al., 1992; Somlo et al., 1992; Peral et al., 1994; Snarey et al., 1994). (Bottom) A detailed map of the distal part of the PKD1 candidate region showing the area of 16p13.3 duplicated in 16p13.1 (hatched); Clal restriction sites (C); the breakpoints in the somatic cell hybrids $N$-OH1 and P-MWH2A; DNA probes; and the TSC2 gene. The limits of the position of the translocation breakpoint found in family 77 (see [b]), determined by evidence of heterozygosity (in 77-4) and by PFGE (see [c] and text) is also indicated. The contig covering the family 77 breakpoint region consists of the following cosmids: 1 , CW9D; 2, ZDS5; 3, JH2A; 4, REP59; 5, JC10.2B; 6, CW10II; 7, SM25A; 8, SMII; 9, NM17.

(b) Pedigree of family 77 , which segregates a 16;22 translocation, showing the chromosomal composition of each subject. Individuals $77-2$ and 77-3 have the balanced products of the exchange and have PKD1; 77-4 is monosomic for $16 \mathrm{p} 13.3 \rightarrow 16$ pter and $22 q 11.21 \rightarrow 22 p t e r$ and has TSC. (c) PFGE of DNA from members of family 77: 77-1 (1), 77-2 (2), 77-3 (3), and 77-4 (4), digested with Clal and hybridized with SM6. In addition to the normal fragments of $340 \mathrm{~kb}$ and partially digested fragment of $480 \mathrm{~kb}$, a proximal breakpoint fragment of approximately $100 \mathrm{~kb}$ (shown by arrow) is seen in individuals $77-2,77-3$, and $77-4$, concordant with segregation of the der(16) chromosome.

lular matrix, and changes in cellular polarity and secretion (reviewed by Gabow, 1991; Wilson and Sherwood, 1991). The primary defect in ADPKD, however, remains unclear, and considerable effort has therefore been applied to identifying the defective gene(s) in this disorder by genetic approaches.

The first step toward positional cloning of an ADPKD gene was the demonstration of linkage of one locus, now designated as the polycystic kidney disease 1 (PKD1) locus, to the $\alpha$-globin cluster on the short arm of chromosome 16 (Reeders et al., 1985). Subsequently, families with ADPKD unlinked to markers of $16 p$ were described (Kimberling et al., 1988; Romeo et al., 1988), and a second ADPKD locus (PKD2) has recently been assigned to chromosome region 4q13-q23 (Kimberling et al., 1993; Peters et al., 1993). It is estimated that approximately $85 \%$ of 


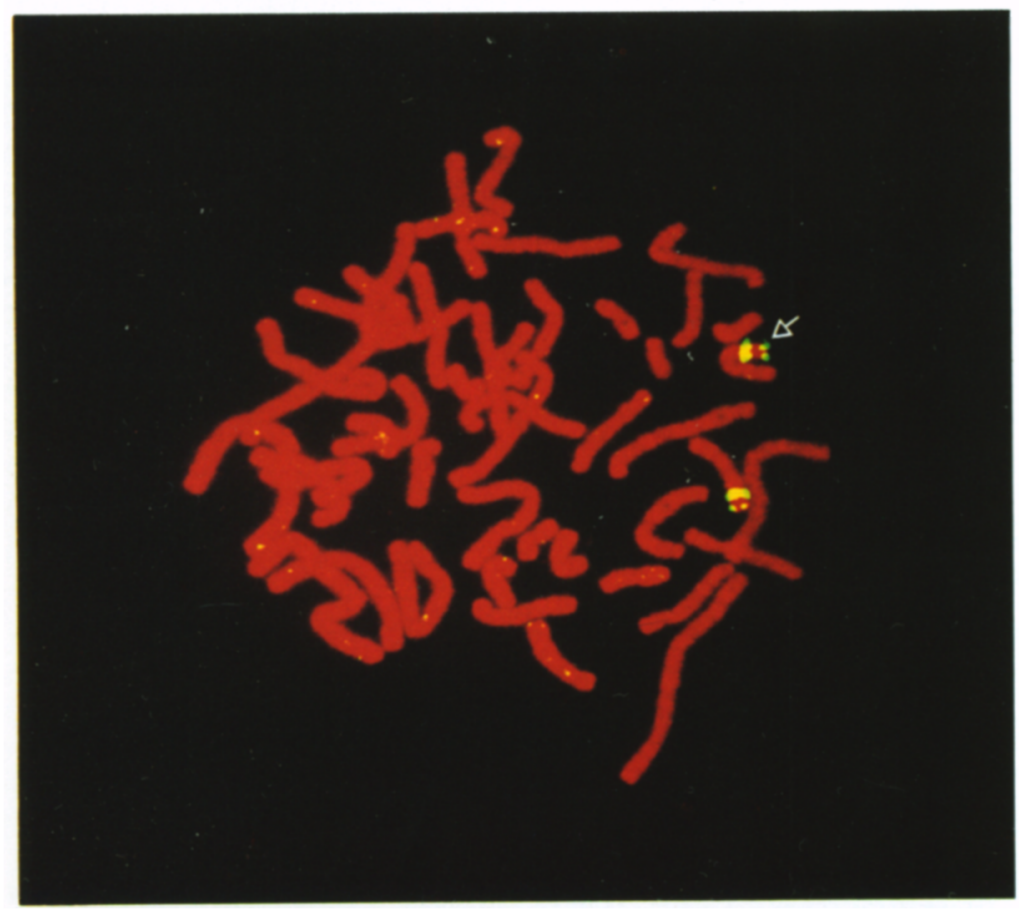

Figure 2. FISH of Cosmid from the Duplicated Area to a Normal Male Metaphase

Duplication of the locus CW10III (cosmid 6 in Figure 1a) is illustrated with two sites of hybridization on 16p; the distal site (the PKD1 region) is shown by an arrow. The signal from the proximal site (16p13.1) is stronger than that from the distal, indicating that sequences homolo gous to CW10III are reiterated in 16p13.1.
ADPKD is due to PKD1 (Peters and Sandkuijl, 1992), with $P K D 2$ accounting for most of the remainder. $P K D 2$ appears to be a milder condition with a later age of onset and ESRD (Parfrey et al., 1990; Gabow et al., 1992; Ravine et al., 1992).

The position of the PKD1 locus was refined to chromosome band 16p13.3, and many markers were isolated from that region (Breuning et al., 1987, 1990; Reeders et al., 1988; Germino et al., 1990; Hyland et al., 1990; Himmelbauer et al., 1991). Their order and the position of the $P K D 1$ locus have been determined by extensive linkage analysis in normal and PKD1 families and by the use of a panel of somatic cell hybrids (Reeders et al., 1988; Breuning et al., 1990; Germino et al., 1990). An accurate long range restriction map (Harris et al., 1990; Germino et al., 1992) has located the PKD1 locus in an interval of approximately $600 \mathrm{~kb}$ between the markers GGG1 and SM7 (Harris et al., 1991; Somlo et al., 1992) (see Figure 1a). The density of CpG islands and identification of many mRNA transcripts indicated that this area is rich in gene sequences. Germino et al. (1992) estimated that the candidate region contains approximately 20 genes.

Identification of the PKD1 gene from within this area has thus proved difficult, and other means to pinpoint the disease gene were sought. Linkage disequilibrium has been demonstrated in a Scottish population between PKD1 and the proximal marker VK5 (Pound et al. , 1992) and in a Spanish population between PKD1 and BLU24 (see Figure 1a) (Peral et al., 1994). Studies with additional markers have shown evidence of a common ancestor in a proportion of each population (Peral et al., 1994; Snarey et al., 1994), but the association has not precisely positioned the PKD1 locus.

Disease-associated genomic rearrangements, detected by cytogenetics or pulsed-field gel electrophoresis (PFGE), have been instrumental in the identification of the genes associated with many genetic disorders. In the case of the tuberous sclerosis (TSC) locus TSC2, which lies within 16p13.3, deletions were detected by PFGE, within the interval thought to contain the PKD1 gene, and their characterization was a significant step toward the rapid identification of the TSC2 gene (European Chromosome 16 Tuberous Sclerosis Consortium, 1993).

We have now identified a pedigree in which the two distinct phenotypes, typical ADPKD or TSC, are seen in different members. In this family the two individuals with ADPKD are carriers of a balanced chromosome translocation with a breakpoint within 16p13.3. We have located the chromosome 16 translocation breakpoint, and a gene disrupted by this rearrangement has been defined; the discovery of additional mutations of that gene in other PKD1 patients shows that we have identified the PKD1 gene.

\section{Results}

\section{A Translocation Associated with ADPKD}

A major pointer to the identity of the PKD1 gene was provided by a Portuguese pedigree (family 77 ) with both ADPKD and TSC (Figure 1b). Cytogenetic analysis showed that the mother, $77-2$, has a balanced translocation, $46 X X$ $t(16 ; 22)(p 13.3 ; q 11.21)$, that was inherited by her daughter, 77-3. The son, $77-4$, has the unbalanced karyotype $45 X Y I$ $-16-22+\operatorname{der}(16)(16 q$ ter $\rightarrow 16 p 13.3:: 22 q 11.21 \rightarrow 22 q t e r)$ and consequently is monosomic for $16 p 13.3 \rightarrow 16$ pter as well as for $22 q 11.21 \rightarrow 22 p t e r$. This individual has the clinical phenotype of TSC (see Experimental Procedures); the 
a

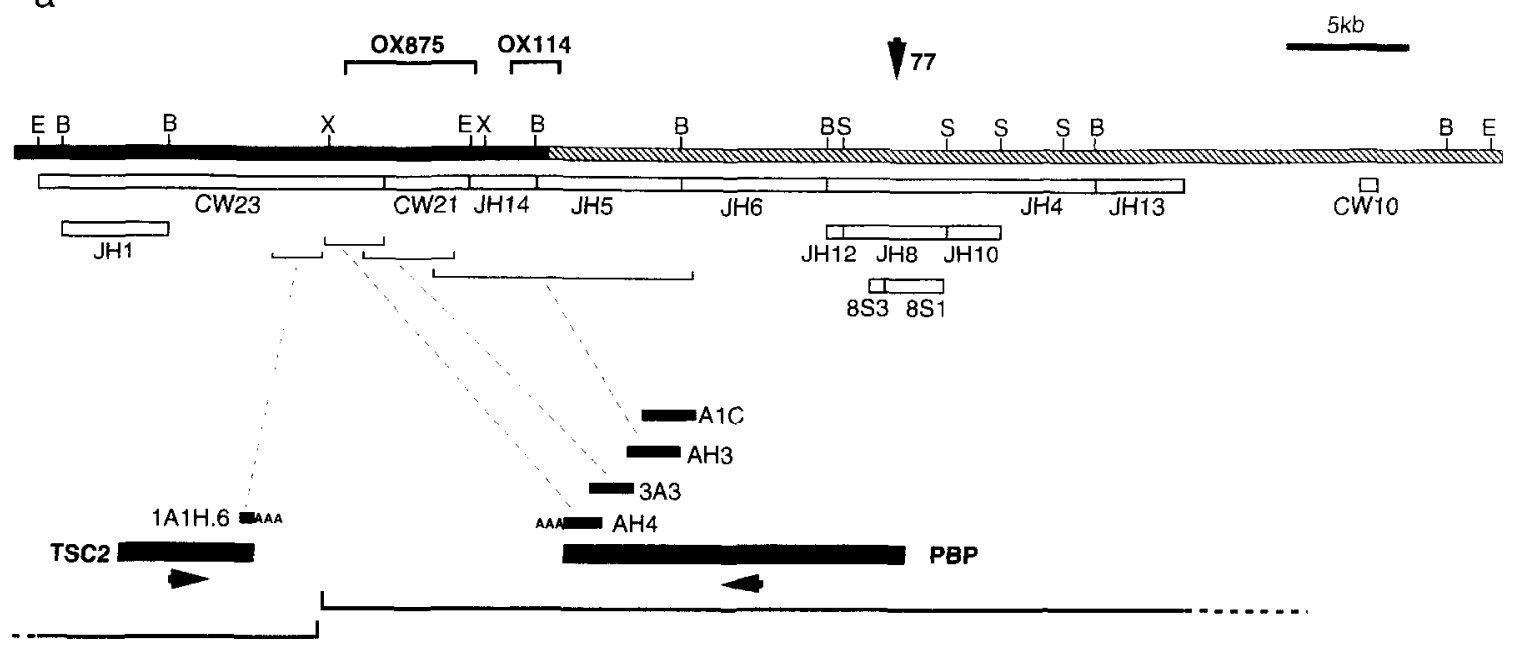

b

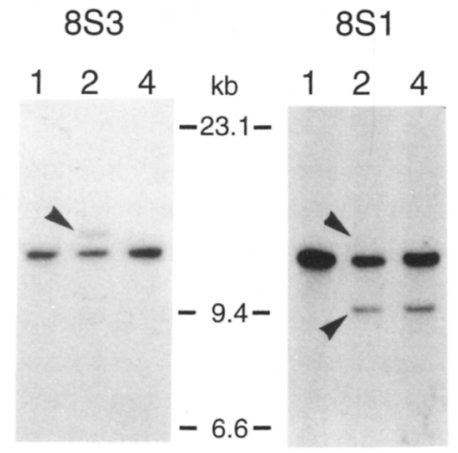

Figure 3. A Detailed Map of the PBP Gene Region Showing the Family 77 Translocation Breakpoint

(a) A detalled map of the transiocation region showing the precise locallzation of the family 77 breakpoint and the region that is duplicated in 16p13.1 (hatched). DNA probes (open boxes), the transcripts PBP and TSC2 (closed boxes; with direction of transcription indicated by an arrow), and cDNAs (stippled boxes) are shown below the genomic map. The known genomic extent of each gene is indicated at the bottom of the diagram, and the approximate genomic locations of each cDNA are indicated under the genomic map. The positions of genomic deletions found in PKD1 patients OX875 and OX114 are also indicated. Restriction sites for EcoRI (E) and incomplete maps for BamHI (B), Sacl (S), and Xbal (X) are shown.

(b) Southern blots of BamHI-digested DNA from individuals 77-1 (1), 77-2 (2), and 77-4 (4) hybridized with 853 (left) and 851 (right) (see [a]). 853 detects a novel fragment on the telomeric side of the breakpoint (12 kb; shown by arrow), associated with the der(22) chromosome in $77-2$, but not $77-4 ; 8 S 1$ identifies a novel fragment on the centromeric side of the breakpoint ( 9 kb; shown by arrow), associated with the der(16) chromosome in 77-2 and 77-4. The telomeric breakpoint fragment is also seen weakly with $8 S 7$ (shown by arrow), indicating that the breakpoint lies in the distal part of $8 S 1$. The $8 S 3$ and $8 S 1$ loci are both duplicated; the normal BamHI fragment detected at the $16 p 13.3$ sile by these probes is $11 \mathrm{~kb}$ (see [a]), but a similarly sized fragment is also detected at the $16 p 13.1$ site. Consequently, the breakpoint fragments are much fainter than the normat (16p13.1 plus 16p13.3) band.

most likely explanation was that the TSC2 locus located within 16p13.3 was deleted in the unbalanced karyotype.

Further analysis revealed that the mother (77-2) and the daughter (77-3) with the balanced translocation have the clinical features of ADPKD (see Experimental Procedures), while the parents of 77-2 (aged 67 and 82 years) were cytogenetically normal, with no clinical features of TSC and no renal cysts on ultrasound examination. Although kidney cysts can be a feature of TSC, no other clinical signs of TSC were identified in 77-2 or 77-3, making it unlikely that the polycystic kidneys were due to TSC. We therefore investigated the possibility that the translocation disrupted the PKD1 locus in 16p13.3 and proceeded to identify and clone the region containing the breakpoint.

Family 77 was analyzed with polymorphic markers from 16p13.3. Individual 77-4 was hemizygous for MS205.2 and GGG1, but heterozygous for SM6 and more proximal markers, locating the translocation breakpoint between GGG1 and SM6 (see Figure 1a). Fluorescence in situ hybridization (FISH) of a cosmid from the TSC2 region, CW9D (cosmid 1 in Figure 1a), to metaphase spreads showed that it hybridized to the der(22) chromosome of 77-2, placing the breakpoint proximal to $C W 9 D$ and indicating that $77-4$ was hemizygous for this region, consistent with his TSC 
phenotype. DNA from members of family 77 was digested with Clal, separated by PFGE, and hybridized with SM6, revealing a breakpoint fragment of $\sim 100 \mathrm{~kb}$ in individuals with the der(16) chromosome (Figure 1c). The small size of this novel fragment enabled the breakpoint to be localized distal to SM6 in a region of just $60 \mathrm{~kb}$ (Figure 1a). A cosmid contig covering this region was therefore constructed (see Experimental Procedures for details).

\section{The Translocation Breakpoint Lies within a Region Duplicated Elsewhere on Chromosome 16 (16p13.1)}

It was previously noted that the region between $C W 21$ and N54 (Figure 1a) was duplicated at a more proximal site on the short arm of chromosome 16 (Germino et al., 1992; European Chromosome 16 Tuberous Sclerosis Consortium, 1993). Figure 2 shows that a cosmid, CW10III, from the duplicated region hybridizes to two points on $16 \mathrm{p}$ : the distal $P K D 1$ region and a proximal site positioned in $16 p 13.1$. The structure of the duplicated area is complex, with each fragment present once in 16p13.3 reiterated two to four times in 16p13.1 (see Figure 2). Cosmids spanning the duplicated area in 16p13.3 were subcloned (see Figure 3a; see Experimental Procedures for details), and a restriction map was generated. A genomic map of the PKD1 region was constructed using a radiation hybrid, Hy145.19, that contains the distal portion of $16 p$ but not the duplicate site in 16p13.1.

To localize the family 77 translocation breakpoint, subclones from the target region were hybridized to DNA from patient $77-2$, digested with Clal, and separated by PFGE. Once probes mapping across the breakpoint were identified, they were hybridized to conventional Southern blots of family 77 DNA. Figure 3b shows that novel BamHI fragments were detected from the centromeric and telomeric side of the breakpoint, which was localized to the distal part of the probe $8 S 1$ (Figure 3a). Hence, the balanced translocation was not associated with a substantial deletion, and the breakpoint was located more than $20 \mathrm{~kb}$ proximal to the TSC2 locus (Figure 3a). These results supported the hypothesis that ADPKD in individuals with the balanced translocation (77-2 and 77-3) was not due to disruption of the TSC2 gene, but indicated that a separate gene mapping just proximal to $T S C 2$ was likely to be the PKD1 gene.

\section{The Polycystic Breakpoint Gene Is Disrupted by the Translocation}

Localization of the family 77 breakpoint identified a precise region in which to look for a candidate for the PKD1 gene. During the search for the TSC2 gene, we identified other transcripts not associated with TSC, including a large transcript $(\sim 14 \mathrm{~kb})$ partially represented in the cDNAs $3 A 3$ and $A H 4$ that mapped to the genomic fragments CW23 and CW21 (Figure 3a). The orientation of the gene encoding this transcript had been determined by the identification of a poly $(A)$ tract in the CDNA, AH4: the $3^{\prime}$ end of this gene lies very close to the TSC gene, in a tail-to-tail orientation (European Chromosome 16 Tuberous Sclerosis Consortium, 1993). To determine whether this gene crossed the translocation breakpoint, genomic probes from within the duplicated area and flanking the breakpoint were hybridized to Northern blots. Probes from both sides of the breakpoint, between $\mathrm{JH} 5$ and $\mathrm{JH} 13$, identified the $14 \mathrm{~kb}$ transcript (Figure 3a; see below for details). Therefore, this gene (previously called $3 A 3$, but now designated the polycystic breakpoint [PBP] gene) extended over the family 77 breakpoint and consequently was a candidate for the PKD1 gene. A walk was initiated to increase the extent of the PBP cDNA contig, and several novel cDNAs were identified using probes from the single copy (nonduplicated) region (see Experimental Procedures for details). A cDNA contig was constructed that extended $\sim 5.7 \mathrm{~kb}$, including $\sim 2 \mathrm{~kb}$ into the area that is duplicated (Figure $3 \mathrm{a}$ ).

\section{Expression of the PBP Gene}

Initial studies of the expression pattern of the PBP gene were undertaken with CDNAs that map entirely within the single copy region (e.g., AH4 and $3 A 3$ ). Figure 4a shows that the $\sim 14 \mathrm{~kb}$ transcript was identified by $3 A 3$ in various tissue-specific cell lines. From this and other Northern blots, we concluded that the PBP gene was expressed in all of the cell lines tested, although often at a low level. The two cell lines that showed the highest level of expression were fibroblasts and a cell line derived from an astrocytoma, G-CCM. Significant levels of expression were also obtained in cell lines derived from kidney (G401) and liver (Hep3B). Measuring the expression of the PBP gene in tissue samples by Northern blotting proved difficult because such a large transcript is susceptible to minor RNA degradation. However, initial results with an RNAase protection assay, using a region of the gene located in the single copy area (see Experimental Procedures), showed a moderate level of expression of the PBP gene in tissue obtained from normal and polycystic kidney (data not shown). The widespread expression of the PBP gene is consistent with the systemic nature of ADPKD.

\section{Identification of Transcripts That Are Partially Homologous to the PBP Transcript}

Novel cDNAs were identified with the genomic fragments, $J H 4$ and $J H 8$, that map to the duplicated region (see Figure 3a; see Experimental Procedures). However, when these cDNAs were hybridized to Northern blots, a more complex pattern than that seen with $3 A 3$ was observed. As well as the $\sim 14 \mathrm{~kb} P B P$ transcript, three other partially homologous transcripts were identified, designated homologous gene $A(H G-A)(\sim 21 \mathrm{~kb}), H G-B(\sim 17 \mathrm{~kb})$, and HG-C (8.5 kb) (Figure 4b). There were two possible explanations for these results: either the $H G$ transcripts were alternatively spliced forms of the PBP gene, or the HG transcripts were encoded by genes located in 16p13.1. To determine the genomic location of the HG loci, a fragment from the $3^{\prime}$ end of one HG CDNA (HG-4/1.1) was isolated. HG-4/1.1 hybridized to all three $H G$ transcripts, but not to the $P B P$ transcript, and on a hybrid panel it mapped to $16 p 13.1$ (not the PKD1 area). These results show that all the $H G$ transcripts are related to each other outside the region of homology with the $P B P$ transcript and that the HG loci map to the proximal site (16p13.1). 
a

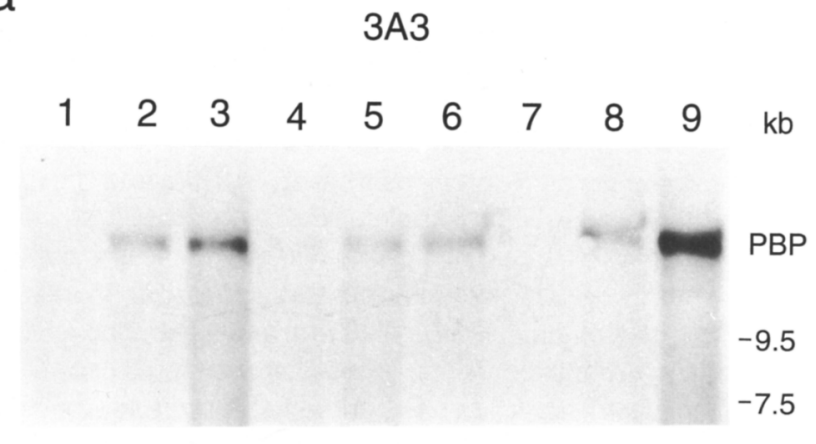

b

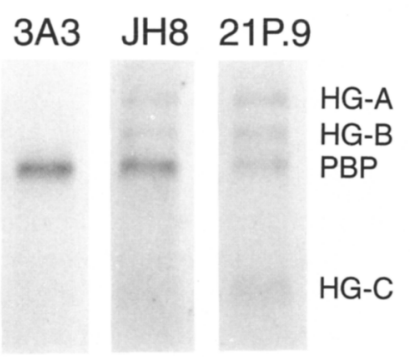

Figure 4. Northern Blot Analysis of the PBP Transcript

(a) PBP cDNA, 3A3, hybridized to a Northern blot containing $-1 \mu \mathrm{g}$ of poly(A)-selected mRNA per lane of the tissue-specific cell lines: lane 1, MJ, Epstein-Barr virus-transformed lymphocytes; lane 2, K562, erythroleukemia; lane 3, FS1, normal fibroblasts; lane 4, HeLa, cervical carcinoma; lane 5, G401, renal Wilm's tumor; lane 6, Hep3B, hepatoma; lane 7, HT29, colonic adenocarcinoma; lane $8,5 W 13$, adre. nal carcinoma; lane 9, G-CCM, astrocytoma A single transcript of approximately $14 \mathrm{~kb}$ is seen; the highest level of expression is in fibroblasts and in the astrocytoma cell line G-CCM. Although in this comparative experiment little expression is seen in lanes 1,4 , and 7 , we have demonstrated at least a low level of expression in these cell lines on other Northern blots and by RT-PCR (see later).

(b) A Northern blot containing $\sim 20 \mu \mathrm{g}$ of total RNA from cell line G-CCM hybridized with CDNAs or a genomic probe that each identify different parts of the PBP gene. (Left) A single $\sim 14 \mathrm{~kb}$ transcript is seen with a cDNA from the single copy area, 3A3. (Right) A cDNA, $21 P .9$, that is homologous to parts of the region that is duplicated $(\mathrm{JH12}, \mathrm{JH}$, and $\mathrm{JH1O}$; see Figure $3 a$ ) hybridizes to the $P B P$ transcript and three novel transcripts: $H G-A(\sim 21 \mathrm{~kb}), H G-B$ ( $-17 \mathrm{~kb})$, and $H G-C(8.5 \mathrm{~kb})$. A similar pattern of transcripts is seen with cDNAs and genomic fragments that nybridize to the area between $\mathrm{JHS}$ and $\mathrm{JH13}$, with the exception of the $\mathrm{JH} 8$ area. (Middle) $J H B$ hybridizes to the transcripts $P B P, H G-A$, and HG-B but not to HG-C

(c) A Northern blot of $20 \mu \mathrm{g}$ of total fibroblast RNA from normal control (N), 77-2 (2), and $77-4$ (4) hybridized with 8S1, which contains the 16;22 translocation breakpoint (see Figure 3). A transcript of $\sim 9 \mathrm{~kb}(P B P .77)$ is identified in the two patients with this translocation, but not in the normal control. PBP-77 is a chimeric PBP transcript formed owing to the transiocation and is not seen in RNA from 77-2 or 77-4 with probes that map distal to the breakpoint.

\section{An Abnormal Transcript Associated with the Family 77 Translocation}

As the PBP gene was transcribed across the region disrupted by the family 77 translocation breakpoint, in a proximal to distal direction on the chromosome (see Figure 3a), it was possible that a novel transcript originating from the $P B P$ promotor would be found in this family. Figure $4 C$ shows that using a probe to the $P B P$ transcript that mapped mainly proximal to the breakpoint, a novel transcript of approximately $9 \mathrm{~kb}(P B P-77)$ derived from the der(16) product of the translocation was detected. Interestingly, the $P B P-77$ transcript appears to be expressed at a higher level than the normal product of $P B P$. These results confirmed that the family 77 translocation disrupts the $P B P$ gene and supports the hypothesis that this is the PKD1 gene.

\section{Mutations of the PBP Gene in Other ADPKD Patients}

To prove that the PBP gene is the defective gene at the PKD1 locus, we analyzed this region for mutations in patients with typical ADPKD. The 3 ' end of the PBP gene was most accessible to study as it maps outside the duplicated area. To screen this region, BamHI digests of DNA from 282 apparently unrelated $A D P K D$ patients were hybridized with the probe $1 A 1 H .6$ (see Figure $3 a$ ). In addition, a large EcoRI fragment $(41 \mathrm{~kb})$ that contains a significant proportion of the PBP gene was assayed by field inversion gel electrophoresis (FIGE) in 167 ADPKD patients, using the probe $C W 10$. Two genomic rearrangements were identified in ADPKD patients by these procedures, each identified by both methods.

The first rearrangement was identified in patient $0 \times 875$ (see Experimental Procedures for clinical details), who was shown to have a $5.5 \mathrm{~kb}$ genomic deletion within the $3^{\prime}$ end of the PBP gene (for details see Figures $5 \mathrm{a}$ and $5 \mathrm{~b}$ and Figure $3 a$ ). This genomic deletion results in an $\sim 3$ $\mathrm{kb}$ internal deletion of the transcript (PBP-875), with the $\sim 500$ bp adjacent to the poly(A) tail intact. In this family, linkage of ADPKD to chromosome 16 could not be proven because although $O \times 875$ has a positive family history of ADPKD, there were no living, affected relatives. However, paraffin-embedded tissue from her affected father (now deceased) was available. We demonstrated, using the polymerase chain reaction (PCR), amplification of a 220 bp fragment spanning the deletion (data not shown), and hence that this individual had the same rearrangement as 
a

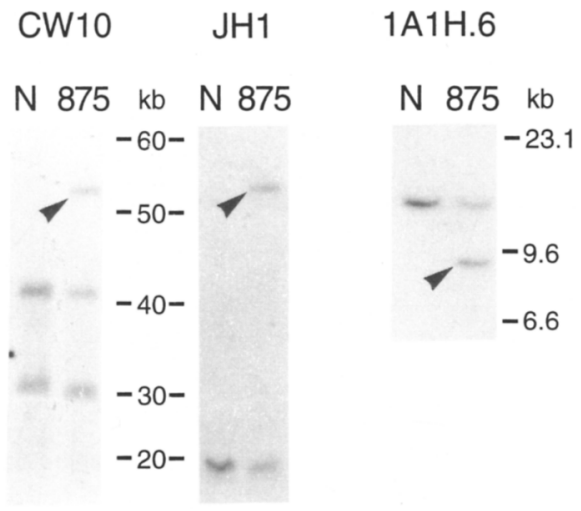

b

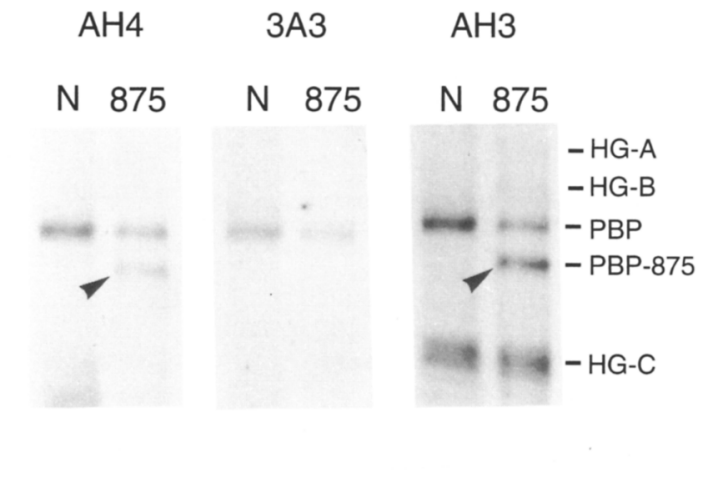

d
CW10

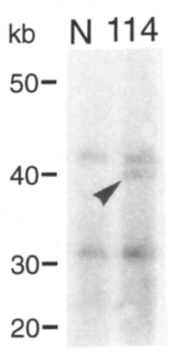

\section{CW21}

N B M 114

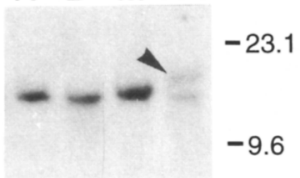

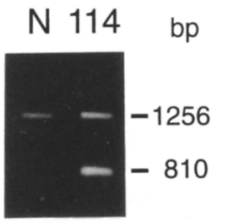

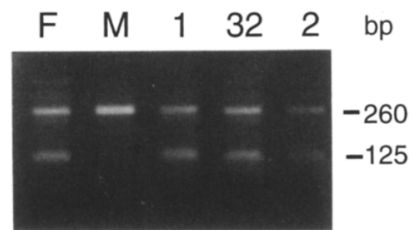

Figure 5. Analysis of Intragenic Mutations of the PBP Gene

(a) FIGE of DNA from normal (N) and ADPKD patient OX875 (875), digested with EcoRI and hybridized with CW1O (left) and JH1 (middle). Normal fragments of $41 \mathrm{~kb}$ (plus a $31 \mathrm{~kb}$ fragment from the 16p13.1 site) (CW1O) and $18 \mathrm{~kb}(\mathrm{JH} 1)$ are identified with these probes; OX875 has an additional $53 \mathrm{~kb}$ band (shown by arrow). The EcoRl site separating these two fragments is removed by the deletion (see Figure $3 a$ ). The right panel shows a Southern blot of BamHl-digested DNA (as above) hybridized with 1A1H.6. A novel fragment of $9.5 \mathrm{~kb}$ is seen in DNA from OX875, as well as the normal $15 \mathrm{~kb}$ fragment. These results indicate that OX875 has a $5.5 \mathrm{~kb}$ deletion; its position was determined more precisely by mapping relative to two Xbal sites that flank the deletion (see Figure $3 a$ ).

(b) Northern blot of total fibroblast RNA, as in (a), hybridized with the cDNAs AH4, 3A3, and AH3. A novel transcript (PBP-875) of $-11 \mathrm{~kb}$ is seen with $A H 4$ (the band is reduced in intensity because the probe is partly deleted) and $A H 3$ (shown by arrow), which flank the deletion, but not $3 A 3$, which is entirely deleted (see Figure 3a). The transcripts HG-A, HG-B, and HG-C, from the duplicated area, are seen with AH3 (see Figure 4b). (c) (Left) FIGE of DNA from normal (N) and ADPKD patient OX114 (114), digested with EcoRI and hybridized with CW10; a novel fragment of 39 $\mathrm{kb}$ (shown by arrow) is seen in OX114. (Middle) DNA, as above, plus the normal mother (M) and brother (B) of OX114, digested with BamHI and hybridized with CW21. A larger than normal fragment of $19 \mathrm{~kb}$ (shown by arrow) was detected in OX114, but not other family members, owing to deletion of a BamHI site; together these results are consistent with a $2 \mathrm{~kb}$ deletion (see Figure 3a). (Right) RT-PCR of RNA, as above, with primers flanking the OX114 deletion (see Experimental Procedures). A novel fragment of $810 \mathrm{bp}$ is seen in OX114, indicating a deletion of 446 bp in the PBP transcript.

(d) RT-PCR of RNA from ADPKD patient OX32 (32) plus the probands, normal mother (M) and affected father (F), and sibs (1) and (2), using the $C$ primer pair from $3 A 3$ (see Experimental Procedures). A novel fragment of 125 bp is detected in each of the affected individuals.

OX875. This result and analysis of two unaffected sibs of OX875 who did not have the deletion showed that this mutation was transmitted with ADPKD.

The second rearrangement detected by hybridization was a 2 kb genomic deletion within the PBP gene, found in ADPKD patient OX114 (see Experimental Procedures for clinical details; see Figures $5 \mathrm{c}$ and $3 \mathrm{a}$ ). No abnormal PBP transcript was identified by Northern blot analysis, but using primers flanking the deletion (see Experimental Procedures), a shortened product was detected by reverse transcription (RT)-PCR (Figure 5c). This was cloned and sequenced and shown to have a frameshift deletion of 446 bp (between base pairs 1746 and 2192 of the sequence shown in Figure 7). OX114 is the only member of the family with ADPKD (she has no children), and ultrasound analysis of her parents at age 78 (father) and age 73 (mother) showed no evidence of renal cysts. Somatic cell hybrids were produced from OX114, and the deleted chromosome was found by haplotype analysis to be of paternal origin. The father of OX114 is now deceased, but analysis of DNA from the brother of OX114 (OX984) with seven microsatellite markers from the PKD1 region (see Experimental Procedures) showed that he shares the same paternal chromosome, in the PKD1 region, as OX114. Renal ultrasound revealed no cysts in OX984 at age 53, and no deletion was detected by DNA analysis (Figure $5 \mathrm{c}$ ). Hence, the 


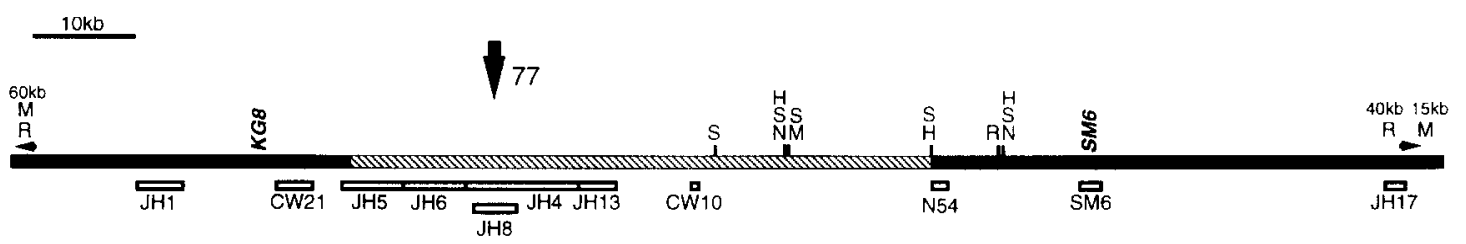

$-\operatorname{TSC2}_{\mathrm{PBP}}-$

Figure 6. Map of the Region Containing the TSC2 and PBP Genes Showing the Area Deleted in Patient WS-53

Localization of the distal end of the WS-53 deletion was previously described (European Chromosome 16 Tuberous Sclerosis Consortium, 1993), and we have now localized the proximal end between SM6 and $J H I 7$. The size of the aberrant Mlul fragment in WS-53, detected by $J H 1$ and $J H 17$, is $90 \mathrm{~kb}$, and these probes lie on adjacent Mlul fragments of $120 \mathrm{~kb}$ and $70 \mathrm{~kb}$, respectively. Therefore, the WS-53 deletion is $\sim 100 \mathrm{~kb}$. Restriction sites for Mlul (M), Nrul (R), and Notl (N) and partial maps for Sacll (S) and BssHII (H) are shown. DNA probes (open boxes) and the TSC2 and $P B P$ transcripts (closed boxes) are indicated below the line with their known genomic extents (brackets). The locations of the microsatellites KG8 and SM6 and the family 77 breakpoint are also indicated.

deletion in OX114 is a de novo event associated with the development of ADPKD. Although it is not possible to show that the ADPKD is chromosome 16 linked, the location of the PBP gene indicates that this is a de novo PKD1 mutation.

To identify more PKD1-associated mutations, we analyzed single copy regions of the PBP gene by RT-PCR using RNA isolated from lymphoblastoid cell lines established from ADPKD patients. CDNA from 48 unrelated patients was amplified with the primer pair $3 A 3 C$ (see Experimental Procedures), and the product of 260 bp was analyzed on an agarose gel. In one patient, $\mathrm{OX} 32$, an additional smaller product (125 bp) was identified, consistent with a deletion or splicing mutation. $0 \times 32$ comes from a large family in which the disease can be traced through three generations. Analysis of RNA from two affected sibs of OX32 and his parents showed that the abnormal transcript segregates with PKD1 (Figure 5d).

Amplification of normal genomic DNA with the $3 A 3 \mathrm{C}$ primers generates a product of $418 \mathrm{bp}$; sequencing showed that this region contains two small introns $\left(5^{\prime}, 75\right.$ bp; $3^{\prime}, 83$ bp) flanking a 135 bp exon. The product amplified from genomic DNA from OX32 was normal in size, excluding a genomic deletion. However, heteroduplex analysis of that DNA revealed larger heteroduplex bands, consistent with a mutation within that genomic interval. The abnormal RT-PCR product from OX32 was cloned and sequenced: this demonstrated that, although present in genomic DNA, the 135 bp exon was missing from the abnormal transcript. Sequencing of OX32 genomic DNA demonstrated a $G \rightarrow C$ transition at +1 of the splice donor site following the $135 \mathrm{bp}$ exon. This mutation was confirmed in all available affected family members by digesting amplified genomic DNA with the enzyme BstNI: a site is destroyed by the base substitution. The splicing defect results in an in-frame deletion of 135 bp from the PBP transcript (3696-3831 bp of the sequence shown in Figure 7). Together, the three intragenic mutations confirm that the $P B P$ gene is the defective gene at the PKD1 locus.

\section{A Deletion That Disrupts the TSC2 and the PKD1 Gene}

We previously identified a deletion (WS-53) that disrupts the TSC2 gene and the PKD1 gene (European Chromosome 16 Tuberous Sclerosis Consortium, 1993), although its full proximal extent was not determined. Further study has shown that the deletion extends $\sim 100 \mathrm{~kb}$ (see Figure 6 for details) and deletes most, if not all, of the PKD1 gene. This patient has TSC but also has unusually severe polycystic disease of the kidneys (full clinical details will be provided in a later paper). Other patients with a similar phenotype are presently under investigation.

\section{Characterization of the PKD1 Gene}

To characterize the PKD1 gene further, evolutionary conservation was analyzed by "zoo blotting." Using probes from the single copy $3^{\prime}$ region ( $\left.3 A 3\right)$ and from the duplicated area ( $\mathrm{JH} 4$ and $\mathrm{JH} 8$ ), the PKD1 gene was conserved in other mammalian species, including horse, dog, pig, and rodents (data not shown). No evidence of related sequences were seen by hybridization at normal stringency in chicken, frog, or fruit fly. The degree of conservation was similar when probes from the single copy or the duplicated region were employed.

The full genomic extent of the PKD1 gene is not yet known, although results obtained by hybridization to Northern blots show that it extends from at least as far as $J H 13$. Several CpG islands have been localized $5^{\prime}$ of the known extent of the PKD1 gene (Figure 6), although there is no direct evidence that any of these are associated with this gene.

The cDNA contig extending 5631 bp to the $3^{\prime}$ end of the PKD1 transcript was sequenced; when possible, more than one cDNA was analyzed, and in all regions both strands were sequenced (Figure 7). We estimate that this accounts for $-40 \%$ of the PKD1 transcript. An open reading frame was detected that runs from the $5^{\prime}$ end of the region sequenced and spans 4842 bp, leaving a $3^{\prime}$ untranslated region of 789 bp that contains the previously de- 


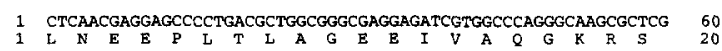

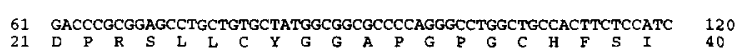

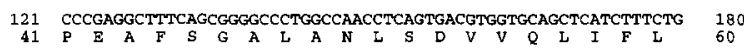

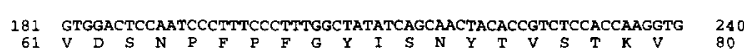

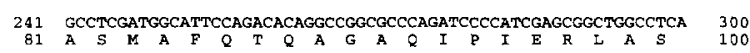

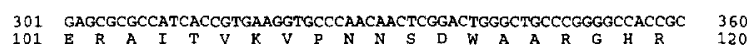

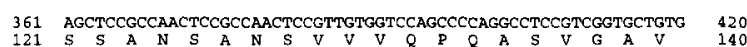

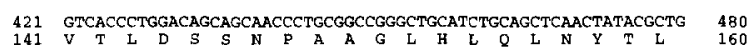

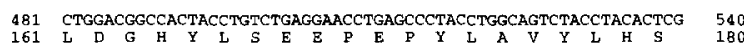

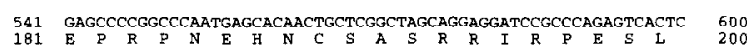

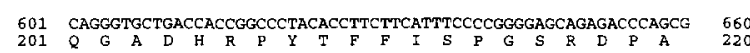

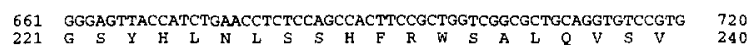

$\begin{array}{llllllllllllllllllllllll}721 & \text { GGCCTGTACACGTCCCTGTGCCAGTACTTCAGCGAGGAGGACATGGTGTGGCGGACAGAG } & 780 \\ 241 & G & L & Y & T & S & L & C & Q & Y & F & S & E & E & D & M & V & W & R & T & E & 260\end{array}$

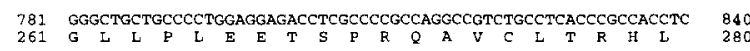

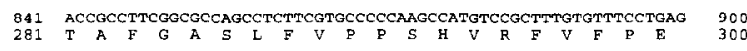

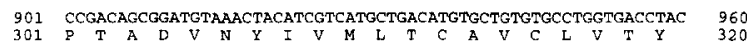

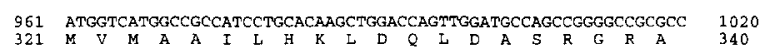

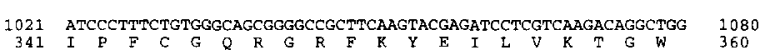

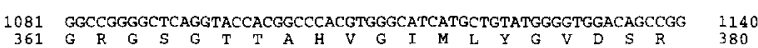

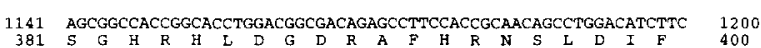

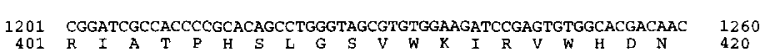

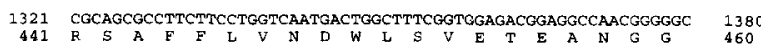

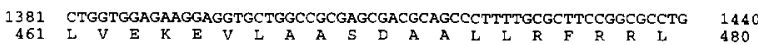

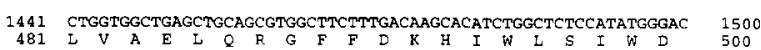

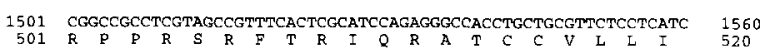

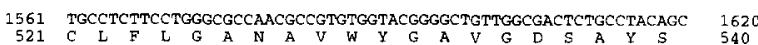

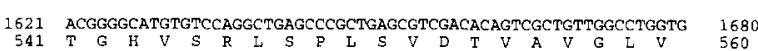

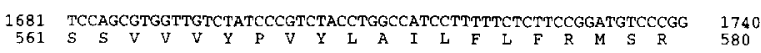

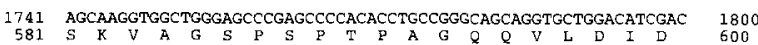

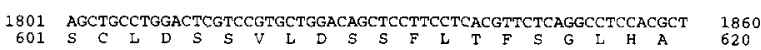

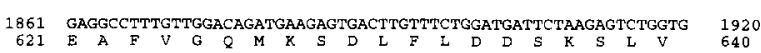

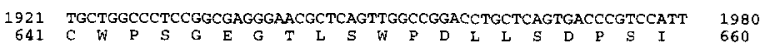

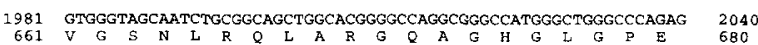

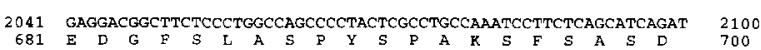

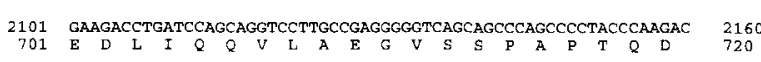

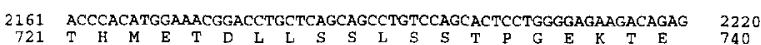

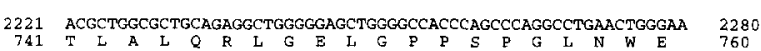

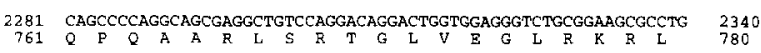

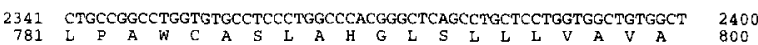

$\begin{array}{rllll}2401 & \text { GTGGCTGTCTCAGGGTGGGTGGTGCGAGCTTCCCCCCGGGCGTAGTGTTGCGTGGCTC } & 2460 \\ 801 & \text { V A V V S G W V G A S F P P G V S V A W L } & 820\end{array}$

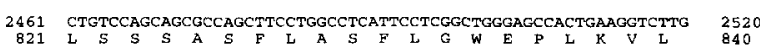

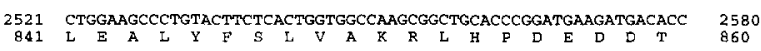

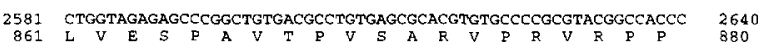

2641 CACGGCTPTGCACTCTTCCTGGCCAAGGAAGAAGCCCGCAAGGTCAAGAGGCTACATGGC 2700

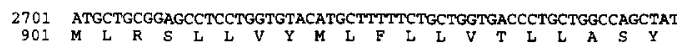

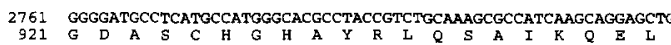

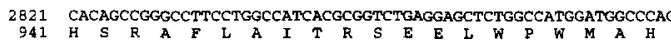

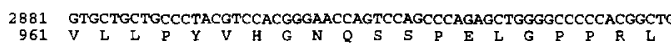

2941
981

3001 TGCTCGGCCGCAGGAGGCTTCAGCACCAGCGATTACGACGTTGGCTGGGAGAGTCCTCAC

3061 AATGGCTCGGGGACGTGGGCCTATTCAGCGCCGGATCTGCTGGGGGCATGGTCCTGGGGC

3121 TCCTGTGCCGTGTATGACAGCGGGGGCACGTGCAGGAGCTGGGCCTGAGCCTGGAGGAG

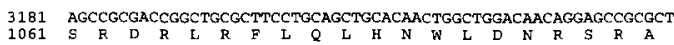

3241 GTGTTCCTTGGAGCTCACGCGCFACAGCCCGGCCGTGGGGCTGCACGCCGCCGTCACGCTO

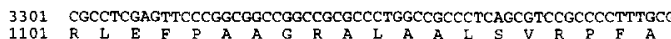

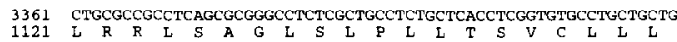

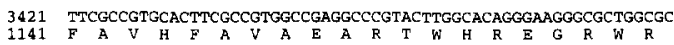

3481 GTGCTGCGGCTCGGAGCCTGGGCGCGGTGCTTGCTGGTGGCGCTGACGGCGCCACGGCA

3541 CTGGTACGCCTCGCCCAGCTGGGTGCCGCTGACCGCCAGTGGACCCGTTTCGTGCGCGGC

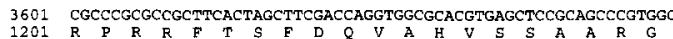

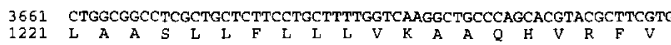

3721 CGCCAGTGGTCCGTCTTTGGCAAGACATTATGCCGAGCTCTGCCAGAGCTCCTGGGGGTC

3781 ACCTTGGGCCTGGTGGTGCTCGGGGTAGCCTACGCCCAGCTGGCCATCCTGCTCGTGTCI

3841 TCCTGTGTGGACTCCCTCTGGAGCGTGGCCCAGGCCCTGTTGGTGCTGTGCCCTGGGACT

3901 GGGCTCTCTACCCTGTGTCCTGCCGAGTCCTGGCACCTGTCACCCCTGCTGTGTGTGGGC
1301 G L S S T L C C P A E S W H L S F L L C V G

1321 L W A L R L W G A L \& L G A V I L R W R

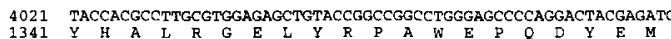

4081 GTGGAGTTSTTCCTGCGCAGGCTGCGCCTCTGGATGGGCCTCAGCAAGGTCAAGGAGTTC
$1361 \mathrm{~V}$

4141
1301
$\mathbb{R}$

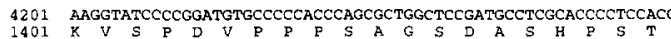

4261 TECTCCAGCCACGTGCATGGGCTGAGCGTGAGCCTGGGCCGGGCTGGCGACAAGGTGTGA

4321 CETGAGCCCTCCCGCCTCCAAGCCGTGTTCGAGGCCCTGCTCACCCAGTTTGACCGACT

4381 AACCAGGCCACAGAGGACGTCTACCAGCTGGAGCAGCAGCTGCACAGCCTGCAGGCCGC
1461 N Q

4441
1481 AGGAGCAGCCGGGCGCCCGCCGGATCTTCCCGTGGCCCATCCCCGGGCCTGCGGCCAGCA

4501 CTGCCCAGCCGCCTTGCCCGGGCCAGTCGGGGTGTGGACCTGGCCACTGGCCCCAGCAGC

4561 ACACCTTCGGGCCAAGAACAACCTCCACCCCAGCAGCACTTACTCCTCCTTCCTGGCGGC

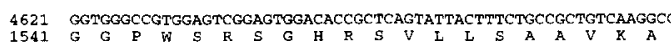

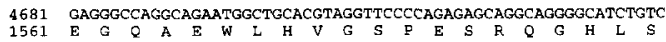

4741 GTCTGTGGGCTTCAGCACTTMAAAGAGGCTGTGTGGCCAACCAGGACCCAGGGTCCCCTC

4801 CCCAGCTCCCTTGGGAAGGACACAGCAGTATTGGACGGTYTCTAGCCTCTGAGATGCTA

4861 TTTATTTCCCCGAGTCCTCAGGTACAGCGGGCTGTGCCCGGCCCCACCCCCTGGGCAGA?

4921 GTCCCCCACTGCTAAGGCTGCTGGCTTCAGGGAGGGTTAGCCTGCACCGCCGCCACCCTG

4981 CCCCTAAGTTATPACCTCTCCAGTTCCTACCGTACTCCCTGCACCGTCTCACTGTGTGTC 5041 TCGTGTCAGTAATTTATATGGTGTTAAAATGTGTATATTTTTGTATGTCACTATTTTCAC

5101 TAGGGCTGAGGGGCCTGCCCCCAGAGCTCGCCTCCCCCAACACCTGCTGCCCTTGGTAG 5161 TGTGGTGGCGTTATGGCAGCCCGGCTGCTGCTTGGATGCGAGCTTGECCTTGGGCCGGTC 5221 CTGGGGGCACAGCTGTCTGCCAGGCACTCTCATCACCCCAGAGGCCTTGTCATCCTCCCT 5281 TGCCCCAGGCCAGGTAGCARGAGAGCAGCGCCCAGGCCTGCTGGCATCAGGTCTGGGCAA

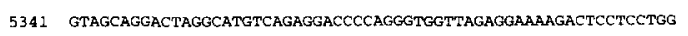
5401 GGGCTGGCTCCCAGGGTGGAGGAAGGTGACTGTGTGTGTGTGTGTGTGCGCGCGCGACGC 5461 GCGAGTGTGCTGTATGGCCCAGGCAGCCTCAAGGCCCTCGGAGCTGGCTGTGCCTGCTTC 5521 TGTGTACCACTTCTGTGGGCATGGCCOCTTCTAGAGCCTCGACACCCCCCCAACCCCCGC 5580 5581 ACCAAGCAGACAAAGTCAaTAAAAGAGCTGTCTGACTGCAAAAAAAAAAAA 5631

\section{920}

2820 960 ${ }_{980}^{2940}$ 3000
1000 3060
1020 3120
1040 3180
1060 3240
1080 3300
1100 3360
1120 3420
1140 3480
1160 3540
1180 3600
1200 3660
1220 3720
1240 3780
1260 3840
1280 3900
1300 3960
1320 ${ }_{1340}^{4020}$ 4080
1360 4140
1380 4200
1400 4260
1420 4320
1440 4380
1460 4440
1480 4500
1500 4560
1520 4620
1540 4680
1560 4740
1580 4800
1600 4860
1620 4920 4980 5040 5100 5160 5220 5280 5340 5400 5460 5520

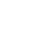


scribed microsatellite KG8 (Peral et al., 1994; Snarey et al., 1994). A polyadenylation signal is present at nucleotides 5598-5603, and a poly(A) tail was detected in two independent CDNAs ( $A H 4$ and $A H 6$ ) at position 5620. Comparison with the cDNAs HG-4 and $11 B H S 21$, which are encoded by genes in the duplicate $16 p 13.1$ region, show that 1866 bp at the $5^{\prime}$ end of the currently known PKD1 sequence lies within the duplicated area. The predicted amino acid sequence from the available open reading frame extends 1614 residues and is shown in Figure 7. A search of the Swiss Prot and NBRF data bases with the available protein sequence using the BLAST program (Altschul et al., 1990) identified only short regions of similarity (notably, between amino acids $690-770$ and $1390-1530$ ) to a diverse group of proteins; no highly significant areas of homology were recognized. The importance of the short regions of similarity is unclear, as the search for protein motifs with the ProSite program did not identify any recognized functional protein domains within the PKD1 gene.

\section{Discussion}

We have presented compelling evidence that mutations of the PBP gene give rise to the typical phenotype of ADPKD. The location of this gene within the PKD1 candidate region and the available genetic evidence from the families with mutations show that this is the PKD1 gene. Four PKD1-associated mutations have been described: a de novo translocation, which was subsequently transmitted with the phenotype; two intragenic deletions (one a de novo event); and a splicing defect. The task of identifying and characterizing the PKD1 gene has been more difficult than for other disorders because more than three quarters of the gene is embedded in a region of DNA that is duplicated elsewhere on chromosome 16. This segment of $40-50 \mathrm{~kb}$ of DNA, present as a single copy in the PKD1 area (16p13.3), is reiterated as several divergent copies in the more proximal region, $16 \mathrm{p} 13.1$. This proximal site contains three gene loci (HG-A, $H G-B$, and $H G-C)$ that each produce polyadenylated $\mathrm{mRNAs}$ and share substantial homology to the PKD1 gene; it is not known whether these partially homologous transcripts are translated into functional proteins.

Although gene amplification is known as a major mechanism for creating protein diversity during evolution, the discovery of a human disease locus embedded within an area duplicated relatively recently is a novel observation. In this case, because of the recent nature of the reiteration, the whole duplicated genomic region retains a high level of homology, not just the exons. The sequence of events leading to the duplication and which sequence represents the original gene locus are not yet clear. However, preliminary evidence of homology of the $3^{\prime}$ ends of the three $H G$ transcripts, which are different from the $3^{\prime}$ end of the PKD1 gene, indicate that the loci in 16p13.1 have probably arisen by further reiteration of sequences at this site, after it separated from the distal locus.

The practical implications of this duplication for isolating and characterizing a full-length transcript and for the detection of PKD1 mutations are considerable. All of the
CDNA libraries screened contain sequences of the PKD1 transcript but also of the three similar HG transcripts; careful comparison of these to the genomic sequence from the $P K D 1$ region will be required to construct a full-length CDNA contig that faithfully represents the entire PKD1 gene. Screening for mutations within the area duplicated is also difficult, whether Southern blotting or a PCR-based assay for base pair changes (e.g., single strand conformation polymorphism or heteroduplex analysis) is employed. In each case the degree of similarity between the duplicate regions means that loci from both areas are detected simultaneously, even if an RT-PCR approach is adopted. In such circumstances slight sequence variations between the duplicate loci are likely to mask variability due to mutation.

Identification of a disease gene does not necessarily provide immediate insight into the pathophysiology of a disorder. Analysis of the available sequence has not highlighted significant homologies to known proteins, so the role of the PKD1 protein remains unclear. It is possible that characterization of the full protein sequence will shed more light on its function. Even the mechanism by which the detected mutations cause PKD1 is not clear. It has previously been argued that PKD1 could be recessive at the cellular level, with a second somatic mutation required to give rise to cystic epithelium (Reeders, 1992). This "two hit" process is thought to be the mutational mechanism giving rise to several dominant diseases, such as neurofibromatosis (Legius et al., 1993) and TSC (Green et al., 1994), that result from a defect in the control of cellular growth. If this were the case, however, we might expect that a proportion of constitutional PKD1 mutations would be inactivating deletions as seen in these other disorders.

Four PKD1 mutations have been characterized, and in each case an abnormal transcript has been identified by Northern analysis or by RT-PCR. Three of these mutations are effectively internal deletions in the $3^{\prime}$ end of the $P K D 1$ gene, one of which is a small in-frame deletion. The location of these mutations may, however, reflect some ascertainment bias as it is this single copy area that has been screened most intensively for mutations. Nevertheless, no additional deletions were detected when a large part of the gene was screened by FIGE, and studies by PFGE showed no large deletions of this area in 75 PKD1 patients. It is possible that the mutations detected so far result in the production of an abnormal protein that causes disease through a gain of function. However, it is also possible that these mutations eliminate the production of functional protein from this chromosome and result in the PKD1 phenotype by haploinsufficiency or only after loss of the second PKD1 homolog by somatic mutation. Clearly, a larger number of mutations need to be studied and the 5 ' end of the gene located and characterized before the full spectrum of PKD1 mutations can be accessed.

One mutation that probably deletes the entire PKD1 gene has been identified (WS-53), but in this case it also disrupts the adjacent $T S C 2$ gene, and the resulting phenotype is of TSC with severe cystic kidney disease. Renal cysts are common in TSC so that the phenotypic significance of deletion of the PKD1 gene in this case is difficult 
to assess. It is clear that not all cases of renal cystic disease in TSC are due to disruption of the PKD1 gene; chromosome 9-linked TSC (TSC1) families also manifest cystic kidneys, and we have analyzed many TSC2 patients with kidney cysts who do not have deletion of the PKD1 gene. A number of patients with TSC and severe cystic kidney disease are presently being analyzed in detail to see whether they also involve disruption of the PKD1 gene.

Familial studies indicate that de novo mutations probably account for only a small minority of all ADPKD cases; a recent study detected five possible spontaneous mutations in 209 families (Davies et al., 1991). However, in our study 1 of 3 intragenic mutations detected was a novel mutation, and the PKD1-associated translocation was also a de novo event. Furthermore, the mutations detected in the two familial cases do not account for a significant proportion of the local PKD1. The OX875 deletion was only detected in 1 of 282 unrelated cases, and the splicing defect was seen in only 1 of 48 unrelated cases. Nevertheless, studies of linkage disequilibrium have found evidence of common haplotypes associated with PKD1 in a proportion of some populations (Peral et al., 1994; Snarey et al., 1994), suggesting that common mutations will be identified.

Once a larger range of mutations has been characterized, it will be possible to evaluate whether the type and location of mutation determines disease severity and whether there is a correlation between mutation and extrarenal manifestations. Previous studies have provided some evidence that the risk of cerebral aneurysms "runs true" in families (Huston et al., 1993) and that some PKD1 families exhibit a consistently mild phenotype (Ryynanen et al., 1987). A recent study has concluded that there is evidence of anticipation in ADPKD families, especially if the disease is transmitted through the mother (Fink ot al., 1994). Furthermore, analysis of families with early manifestation of ADPKD show that there is a significant intrafamilial recurrence risk and that childhood cases are most often transmitted maternally (Fink et al., 1993; Zerres et al., 1993). This pattern of inheritence is reminiscent of that seen in diseases in which an expanded trinucleotide repeat was found to be the mutational mechanism (reviewed by Mandel, 1993). However, no evidence for an expanding repeat correlating with PKD1 has been found in this region, although such a sequence cannot be excluded.

There is ample evidence that early presymptomatic diagnosis of $P K D 1$ is helpful because it allows complications such as hypertension and urinary tract infections to be monitored and treated quickly (Ravine et al., 1991). The identification of mutations within a family will allow rapid screening of that and other families with the same mutation. Given the difficulties of identifying mutations in this region, however, genetic linkage analysis is likely to remain important for presymptomatic diagnosis. The accuracy and ease of linkage-based diagnosis will be improved by the identification of the PKD1 gene: a microsatellite lies in the $3^{\prime}$ untranslated region of this gene (KG8), and several CA repeats are located 5 ' of the gene (see Figures $1 \mathrm{a}$ and 6; Peral et al., 1994; Snarey et al., 1994).
The identification of the PKD1 gene is a first step toward understanding the molecular pathology of this complex disorder. Characterization of a full-length transcript and definition of the full range of mutations that cause PKD1 are now required, progress that is likely to be impeded because this area is duplicated. The information now available will, however, allow study of the PKD1 protein to determine both its normal role in the cell and the mechanism by which mutation of the PKD1 gene causes the major renal cystic disease in humans.

\section{Experimental Procedures}

\section{Clinical Detalis of Patlents}

Family 77

Patients $77-2$ and $77-3$ are 48 and 17 years old, respectively, and have typical ADPKD. Both have bilateral polycystic kidneys, and 77-2 has impaired renal function. Neither patient manifests any signs of TSC (apart from cystic kidneys) on clinical and ophthalmological examination or by a computerized tomography scan of the brain.

Patient $77-4$ is 13 years old and severely mentally retarded and has multiple signs of TSC, including adenoma sebaceum, depigmented macules, and periventricular calcification on computerized tomography scan. Renal ultrasound reveals a small number of bilateral renal cysts.

\section{ADPKD Patlents}

Patient OX875, age 46, developed ESRD from ADPKD. Progressive decline in renal function has been observed over 17 years; ultrasound examinations documented enlarging polycystic kidneys with less ex tensive hepatic cystic disease. Both kidneys were removed after renal transplantation, and pathological examination showed typical advanced cystic disease in kidneys weighing $1920 \mathrm{~g}$ and $3450 \mathrm{~g}$ (normal average, $120 \mathrm{~g}$ ).

Patient OX114, age 54, developed ESRD from ADPKD: diagnosis was made by radiological investigation during an episode of abdominal pain at age 25. A progressive decline in renal function and the development of hypertension were subsequently observed. Ultrasonic examination demonstrated enlarged kidneys with typical cystic disease, with less severe hepatic involvement.

Patient $0 \times 32$ is a member of a large kindred affected by typical ADPKD in which several members have developed ESRD. The patient himself has been observed for 12 years, with progressive renal failure and hypertension following ultrasonic demonstration of polycystic kidneys.

No signs of TSC were observed on clinical examination of any of the ADPKD patients.

\section{DNA Electrophoresis and Hybridization}

DNA extraction, restriction digests, electrophoresis, Southern blotting hybridization, and washing were performed by standard methods or as previously described (Harris et al., 1990). FIGE was performed with the Bio-Rad FIGE mapper using program 5 to separate fragments from $25-50 \mathrm{~kb}$. High molecular weight DNA for PFGE was isolated in agarose blocks and separated on the Bio-Rad CHEF DRII apparatus using appropriate conditions.

\section{Genomic DNA Probes and Somatic Cell Mybrids}

Many of the DNA probes used in this study have been described previously: MS205. 2 (D16S309; Royle et al., 1992); GGG1 (D165259; Germino et al., 1990); N54 (D16S139; Himmelbauer et al., 1991); and SM6 (D16S665), CW23, CW21, and JH1 (European Chromosome 16 Tuberous Sclerosis Consortium, 1993). Microsatellite probes for haplotype analysis were KG8 and W5.2 (Snarey et al., 1994); SM6, CW3, and CW2 (Peral et al., 1994); 16AC2.5 (Thompson ot al., 1992); SM7 (Harris et al., 1991); and VK5AC (Aksentijevich et al., 1993).

Probes isolated during this study were $J H 4, J H 5$, and $J H 6(11 \mathrm{~kb}$, $6 \mathrm{~kb}$, and $6 \mathrm{~kb}$ BamHI fragments, respectively) and $\mathrm{JH} 13$ and $\mathrm{JH} 14$ ( $4 \mathrm{~kb}$ and $2.8 \mathrm{~kb}$ BamHI-EcoRl fragments, respectively), all from the cosmid $\mathrm{JH} 2 \mathrm{~A} ; \mathrm{JH} 8$ and $\mathrm{JH} 10$ are $4.5 \mathrm{~kb}$ and $2 \mathrm{~kb}$ Sacl fragments, respectively, and $J H 12$ is a $0.6 \mathrm{Sacl}-\mathrm{BamHI}$ fragment, all from $\mathrm{JH} 4$; $8 S 1$ and $8 S 3$ are $2.4 \mathrm{~kb}$ and $0.6 \mathrm{~kb}$ Sacll fragments, respectively, from 
JH8; CW10 is a $0.5 \mathrm{~kb}$ Notl-Mlul fragment of SM25A; JH17 is a $2 \mathrm{~kb}$ EcoRI fragment of NM17.

The somatic cell hybrids $\mathrm{N}-\mathrm{OH} 1$ (Germino et al., 1990), P-MWH2A (European Chromosome 16 Tuberous Sclerosis Consortium, 1993) and Hy 745.19 (Himmelbauer et al., 1991) have previously been described. Somatic cell hybrids containing the paternally derived (BP210) and maternally derived (BP2-9) chromosomes from OX114 were produced by the method of Deisseroth and Hendrick (1979).

\section{Constructing a Cosmid Contig}

Cosmids were isolated from chromosome 16-specific and total genomic libraries, and a contig was constructed using the methods and libraries previously described (European Chromosome 16 Tuberous Sclerosis Consortium, 1993). To ensure that cosmids were derived from the $16 \mathrm{p} 13.3$ region (not the duplicate $16 p 13.1$ area), initially probes from the single copy area were used to screen libraries (e.g., CW21 and N54). Two cosmids mapped entirely within the area duplicated, CW1OIII and JC10.2B. To establish that these were from the $P K D 1$ area, they were restriction mapped and hybridized with the probe CW10. The fragment sizes detected were compared with results obtained with hybrids containing only the 16p13.3 area (Hy145.19) or only the $16 p 13.1$ region $(P-M W H 2 A)$.

FISH

FISH was performed essentially as previously described (Buckle and Rack, 1993). The hybridization mixture contained $100 \mathrm{ng}$ of biotin IIdUTP-labeled cosmid DNA and $2.5 \mu \mathrm{g}$ of human Cot-1 DNA (Bethesda Research Laboratories), which was denatured and annealed at $37^{\circ} \mathrm{C}$ for $15 \mathrm{~min}$ prior to hybridization at $42^{\circ} \mathrm{C}$ overnight. After stringent washes, the site of hybridization was detected with successive layers of fluorescein-conjugated avidin $(5 \mu \mathrm{g} / \mathrm{ml})$ and biotinylated anti-avidin $(5 \mu \mathrm{g} / \mathrm{ml})$ (Vector Laboratories). Slides were mounted in Vectashield (Vector Laboratories) containing $1 \mu \mathrm{g} / \mathrm{ml}$ propidium iodide and $1 \mu \mathrm{g}$ $\mathrm{ml} 4^{\prime}, 6^{\prime}$-diamidino-2-phenylindole (DAPI) to allow concurrent G-banded analysis under UV light. Results were analyzed and images captured using a Bio-Rad MRC 600 confocal laser scanning microscope.

\section{cDNA Screening and Characterization}

Fetal brain cDNA libraries in $\lambda$ phage (Clonetech; Stratagene) were screened by standard methods with genomic fragments in the single copy area (equivalent to $C W 23$ and $C W 21$ ) or with a $0.8 \mathrm{~kb}$ Pvull-EcoRI single copy fragment of $A H 3$. Six PBP cDNAs were characterized, including two previously described cDNAs, $A H 4(1.7 \mathrm{~kb})$ and $3 A 3(2.0$ kb) (European Chromosome 16 Tuberous Sclerosis Consortium, 1993), and four novel CDNAs, AH3 (2.2 kb), AH6 (2.0 kb), A1C (2.2 $\mathrm{kb})$, and $B 1 E(2.9 \mathrm{~kb})$. A Striatum library (Stratagene) was screened with $J H 4$, and an $H G-C$ CDNA, $11 B H S 21$ (3.8 kb), was isolated; $21 P .9$ is a $0.9 \mathrm{~kb}$ Pvull-EcoRl subclone of this CDNA. A HG-A or HG-B cDNA, HG-4 ( $7 \mathrm{~kb}$ ), was also isolated by screening the fetal brain library (Stratagene) with $J H 8$. HG-4/1. 1 is a $1.1 \mathrm{~kb}$ Pvull-EcoRI fragment from the $3^{\prime}$ end of HG-4. 1A1H.6 is a 0.6 kb Hindlll-EcoRI subclone of a TSC2 CDNA, 1A-1 $(1.7 \mathrm{~kb})$, which was isolated from the Clonetech library. Each cDNA was subcloned into Bluescript and sequenced utilizing a combination of sequential truncation and oligonucleotide primers using DyeDeoxy' Terminators (Applied Biosystems) and an AB| 373A DNA Sequencer (Applied Biosystems) or by hand with Sequenase T7 DNA polymerase (U. S. Biochemicals).

\section{RNA Procedures}

Total RNA was isolated from cell lines and tissues by the method of Chomczynski and Sacchi (1987), and enrichment for mANA was made using the poly(AT) tract mRNA isolation system (Promega). For RNA electrophoresis, $0.5 \%$ agarose denaturing formaldehyde gels were used that were Northern blotted, hybridized, and washed using standard procedures. The $0.24-9.5 \mathrm{~kb}$ RNA (GIBCO BRL) size standard was used, and hybridization of the probe (1-9B3) to the $13 \mathrm{~kb}$ utrophin transcript (Love et al., 1989) in total fibroblast RNA was used as a size marker for the large transcripts.

RT-PCR was performed with $2.5 \mu \mathrm{g}$ of total RNA by the method of Brown et al. (1990) with random hexamer primers, except that AMV reverse transcriptase (Life Sciences) was employed. To characterize the deletion of the PBP transcript in OX114, we used the following primers: AH3F9, 5'-TTT GAC AAG CAC ATC TGG CTC TC-3'; AH3B7,
5'-TAC ACC AGG AGG CTC CGC AG-3'. These were emplyed in a DMSO-containing PCR buffer (Dodé et al., 1990) with $0.5 \mathrm{mM} \mathrm{MgCl}$ and 36 cycles of $94^{\circ} \mathrm{C}$ for $1 \mathrm{~min}, 61^{\circ} \mathrm{C}$ for $1 \mathrm{~min}$, and $72^{\circ} \mathrm{C}$ for $2 \mathrm{~min}$ plus a final extension of $10 \mathrm{~min}$.

The $3 A 3 C$ primers used to amplify the CDNA from OX32 and DNA were these: $3 A 3$ C1, 5'-CGC CGC TTC ACT AGC TTC GAC-3; $3 A 3$ C2, 5'-ACG CTC CAG AGG GAG TCC AC-3'. These were employed in a PCR buffer and cycle previously described (Harris et al., 1991) with $1 \mathrm{mM} \mathrm{MgCl}$ and an annealing temperature of $61^{\circ} \mathrm{C}$.

PCR products for sequencing were amplified with Pful (Stratagene) and ligated into the Srfl site in PCR-Script (Stratagene) in the presence of Srfl.

\section{RNAase Protection}

Tissues from normal and end stage polycystic kidneys were immediately homogenized in guanidinium thiocyanate. RNA was purified on a cesium chloride gradient, and $30 \mu \mathrm{g}$ of total RNA was assayed by RNAase protection by the method of Melton et al. (1984) using a genomic template generated with the $3 A 3 C$ primers.

\section{Heteroduplex Analysis}

Heteroduplex analysis was performed essentially as described by Keen et al. (1991). Samples were amplified from genomic DNA with the $3 A 3 \mathrm{C}$ primers, heated at $95^{\circ} \mathrm{C}$ for $5 \mathrm{~min}$, and incubated at room temperature for at least $30 \mathrm{~min}$ before loading on a Hydrolink gel (AT Biochem). Hydrolink gels were run for $12-18 \mathrm{hr}$ at $250 \mathrm{~V}$ and fragments observed after staining with ethidium bromide.

Extraction and Amplification of Paraffin-Embedded DNA

DNA from formalin-fixed, paraffin wax-embedded kidney tissue was prepared by the method of Wright and Manos (1990), except that after proteinase $\mathrm{K}$ digestion overnight at $55^{\circ} \mathrm{C}$, the DNA was extracted with phenol plus chloroform before ethanol precipitation. Approximately 50 ng of DNA was used for PCR with $1.5 \mathrm{mM} \mathrm{MgCl}_{2}$ and 40 cycles of $94^{\circ} \mathrm{C}$ for $1 \mathrm{~min}, 59^{\circ} \mathrm{C}$ for $1 \mathrm{~min}$, and $72^{\circ} \mathrm{C}$ for $40 \mathrm{~s}$, plus a $10 \mathrm{~min}$ extension at $72^{\circ} \mathrm{C}$

The oligonucleotide primers designed to amplify across the genomic deletion of OX875 were as follows: AH4F2, 5'-GGG CAA GGG AGG ATG ACA AG-3'; JH1483, 5'-GGG TIT ATC AGC AGC AAG CGG-3' These produced a product of $\sim 220 \mathrm{bp}$ in individuals with the $O \times 875$ deletion.

\section{Acknowledgments}

We particularly thank Dr. C. G. Winearls, C. Strong, and K. Clark for their important contributions to the project and Prof. Sir D. J. Weatherall, Prof. G. J. B. van Ommen, Prof. P. Harper, and Prof. H. Galjaard for continued support. R. Snell, D. Shaw, A. O. M. Wilkie, K. Fleming, and D. Ravine are thanked for helpful discussions; D. R. M. Lindsell, A. Cahill, J. Fawcett, and W. Landells for assistance with collection of clinical material; $P$. Thompson for cytogenetics; and V. Chowdhury and $\mathrm{R}$. Boone for technical advice. D. J. Blake and I. Ceccherini contributed important reagents, and L. Rose is thanked for administrative assistance. We also thank the patients, families, and doctors who have contributed to this project and without whom this study would not have been possible. This work was supported financially by the Medical Research Council, the Wellcome Trust, the Oxford Kidney Unit Trust Fund, the Dutch Kidney Foundation, the Prevention Fund (The Netherlands), the Tuberous Sclerosis Association, Action Research, the University of Wales, and The Netherlands Organization for Scientific Research.

Received May 6, 1994; revised May 20, 1994

\section{References}

Aksentijevich, I., Pras, E., Gruberg, L., Shen, Y., Holman, K., Helling, S., Prosen, L., Sutherland, G. R., Richards, R. I., Ramsburg, M., Dean, M., Pras, M., Amos, C. I., and Kastner, D. L. (1993). Refined mapping of the gene causing familial Mediterranean fever, by linkage and homozygosity studies. Am. J. Hum. Genet. 53, 451-461.

Altschul, S. F., Warren, G., Miller, W., Myers, E. W., and Lipman, D. J. (1990). Basic alignment search tool. J. Mol. Biol. 215, 403-410. 
Breuning, M. H., Reeders, S. T., Brunner, H., ljdo, J. W., Saris, J. J., Verwest, A., van Ommen, G. J. B., and Pearson, P. L. (1987). Improved early diagnosis of adult polycystic kidney disease with flanking DNA markers. Lancet $i i, 1359-1361$.

Breuning, M. H., Snijdewint, F. G. M., Brunner, H., Verwest, A., ljdo, J. W., Saris, J. J., Dauwerse, J. G., Blonden, L., Keith, T., Callen D. F., Hyland, V. J., Xiao, G. H., Scherer, G., Higgs, D. R., Harris, P., Bachner, L., Reeders, S. T., Germino, G., Pearson, P. L., and van Ommen, G. J. B. (1990). Map of 16 polymarphic loci on the short arm of chromosome 16 close to the polycystic kidney disease gene (PKD1). J. Med. Genet. 27, 603-613.

Brown, C. J., Flenniken, A. M., Williams, B. R. G., and Willard, H. F. (1990). $X$ chromosome inactivation of the human TIMP gene. Nucl. Acids Res. 18, 4191-4195.

Buckle, V. J., and Rack, K. (1993). Fluorescent in situ hybridisation. In Human Genetic Disease Analysis: A Practical Approach, Volume 2, K. E. Davies, ed. (Oxford: IRL Press), pp. 59-82.

Chapman, A. B., Rubinstein, D., Hughes, R., Stears, J. C., Earnest, M. P., Johnson, A. M., Gabow, P. A., and Kaehny, W. D. (1992). Intracranial aneurysms in autosomal dominant polycystic kidney disease. N. Engl. J. Med. 327, 916-920.

Chomczynski, P., and Sacchi, N. (1987). Single-step method of RNA isolation by acid guanidinium thiocyanate-phenol-chloroform extraction. Anal. Biochem. 162, 156-159.

Dalgaard, O. Z. (1957). Bilateral polycystic disease of the kidneys: a follow-up of two hundred and eighty-four patients and their families. Acta Med. Scand. (Suppl.) 328, 1-251.

Davies, F., Coles, G. A., Harper, P. S., Williams, A. J., Evans, C., and Cochlin, D. (1991). Polycystic kidney disease re-evaluated: a population-based study. Quart. J. Med. 79, 477-485.

Deisseroth, A., and Hendrick, D. (1979). Activation of phenotypic expression of human globin genes from non-erythroid cells by chromosome-dependent transfer to tetraploid mouse erythroleukemia cells. Proc. Natl. Acad. Sci. USA 76, 2185-2189.

Dodé, C., Rochette, J., and Krishnamoorthy, R. (1990). Locus assignment of human $\alpha$ globin mutations by selective amplification and direct sequencing. Br. J. Haemat. 76, 275-281.

European Chromosome 16 Tuberous Sclerosis Consortium (1993). Identification and characterization of the tuberous sclerosis gene on chromosome 16. Cell 75, 1305-1315.

Fink, G. M., Johnson, A. M., Strain, J. D., Kimberling, W. J., Kumar, S., Manco-Johnson, M. L., Duley, I. T., and Gabow, P. A. (1993). Characteristics of very early onset autosomal dominant polycystic kidney disease. J. Am. Soc. Nephrol. 3, 1863-1870.

Fink, G. M., Johnson, A. M., and Gabow, P. A. (1994). Is there evidence for anticipation in autosomal-dominant polycystic disease? Kidney Int. 45, 1153-1162.

Gabow, P. A. (1990). Autosomal dominant polycystic kidney disease: more than a renal disease. Am. J. Kidney Dis. 16, 403-413.

Gabow, P. A. (1991). Polycystic kidney disease: clues to pathogenesis. Kidney Int. 40, 989-996.

Gabow, P. A. (1993). Autosomal dominant polycystic kidney disease. N. Engl. J. Med. 329, 332-342.

Gabow, P. A., Johnson, A. M., Kaehny, W. D., Kimberling, W. J., Lezotte, D. C., Duley, I. T., and Jones, R. H. (1992). Factors affecting the progression of renal disease in autosomal-dominant polycystic kidney disease. Kidney Int. 41, 1311-1319.

Germino, G. G., Barton, N. J., Lamb, J., Higgs, D. R., Harris, P., Xiao, G. H., Scherer, G., Nakamura, Y., and Reeders, S. T. (1990). Identification of a locus which shows no genetic recombination with the autosomal dominant polycystic kidney disease gene on chromosome 16. Am. J. Hum. Genet. 46, 925-933.

Germino, G. G., Weinstat-Saslow, D., Himmelbauer, H., Gillespie, G. A. J., Somlo, S., Wirth, B., Barton, N., Harris, K. L., Frischauf, A.-M., and Reeders, S. T. (1992). The gene for autosomal dominant polycystic kidney disease lies in a 750-kb CpG-rich region. Genomics 13, 144151.

Green, A. J., Smith, M., and Yates, J. R. W. (1994). Loss of heterozygosity on chromosome $16 \mathrm{p} 13.3$ in hamartomas from tuberous sclero- sis patients. Nature Genet. 6, 193-196.

Harris, P. C., Barton, N. J., Higgs, D. R., Reeders, S. T., and Wilkie, A. O. M. (1990). A long-range restriction map between the $\alpha$-globin complex and a marker closely linked to the polycystlc kidney disease 1 (PKD1) locus. Genomics 7, 195-206.

Harris, P. C., Thomas, S., Ratcliffe, P. J., Breuning, M. H., Coto, E. and Lopez-Larrea, C. (1991). Rapid genetic analysis of families with polycystic kidney disease $\uparrow$ by means of a microsatellite marker. Lancet 338, 1484-1487.

Himmelbauer, H., Germino, G. G., Ceccherini, I., Romeo, G., Reeders, S. T., and Frischauf, A.-M. (1991). Saturating the region of the polycystic kidney disease gene with Notl linking clones. Am. J. Hum. Genet. 48, 325-334.

Hossack, K. F., Leddy, C. L., Johnson, A. M., Schrier, R. W., and Gabow, P. A. (1988). Echocardiographic findings in autosomal dominant polycystic kidney disease. N. Engl. J. Med. 319, 907-912.

Huston, J., Torres, V. E., Sulivan, P. P., Offord, K. P., and Wiebers, D. O. (1993). Value of magnetic resonance angiography for detection of intracranial aneurysm in autosomal dominant polycystic kidney disease. J. Am. Soc. Nephrol. 3, 1871-1877.

Hyland, V. J., Suthers, G. K., Friend, K., MacKinnon, R. N., Callen D. F., Breuning, M. H., Keith, T., Brown, V. A., Phipps, P., and Sutherland, G. R. (1990). Probe, VK5B, is located in the same interval as the autosomal dominant adult polycystic kidney disease locus, $P K D 1$. Hum. Genet. 84, 286-288.

Keen, J., Lester, D., Inglehearn, C., Curtis, A., and Bhattacharya, S. (1991). Rapid detection of single base mismatches as heteroduplexes on Hydrolink gels. Trends Genet. 7, 5.

Kimberling, W. J., Fain, P. R., Kenyon, J. B., Goldgar, D., Sujansky, E., and Gabow, P.A. (1988). Linkage heterogeneity of autosomal dominant polycystic kidney disease. N. Engl. J. Med. 319, 913-918.

Kimberling, W. J., Kumar, S., Gabow, P. A., Kenyon, J. B., Connolly, C. J., and Somlo, S. (1993). Autosomal dominant polycystic kidney disease: localization of the second gene to chromosome $4 q 13-q 23$. Genomics 18, 467-472.

Legius, E., Marchuk, D. A., Collins, F. S., and Glover, T. W. (1993). Somatic deletion of the neurofibromatosis type $1 \mathrm{gene}$ in a neurofibrosarcoma supports a tumour suppressor gene hypothesis. Nature Genet. 3, 122-126.

Love, D. R., Hill, D. F., Dickson, G., Spurr, N. K., Byth, B. C., Marsden, R. F., Walsh, F. S., Edwards, Y. H., and Davies, K. E. (1989). An autosomal transcript in skeletal muscle with homology to dystrophin. Nature 339, 55-58.

Mandel, J.-L. (1993). Questions of expansion. Nature Genet. 4, 8-9. Melton, D. A., Kreig, P. A., Rebagliati, M. R., Maniatis, T., Zinn, K. and Green, M. R. (1984). Efficient in vitro synthesis of biological active RNA and RNA hybridization probes from plasmids containing a bacteriophage SP6 promoter. Nucl. Acid Res. 12, 7035-7056.

Milutinovic, J., Fialkow, P. J., Rudd, T. G., Agodoa, L. Y., Phillips, L. A., and Bryant, J. I. (1980). Liver cysts in patients with autosomal dominant polycystic kidney disease. Am. J. Med. 68, 741-744.

Parfrey, P. S., Bear, J. C., Morgan, J., Cramer, B. C., McManamon, P. J., Gault, M. H., Churchill, D. N., Singh, M., Hewitt, R., Somlo, S., and Reeders, S. T. (1990). The diagnosis and prognosis of autosomal dominant polycystic kidney disease. N. Engl. J. Med. 323, 1085-1090. Peral, B., Ward, C. J., San Millán, J. L., Thomas, S., Stallings, R. L., Moreno, F., and Harris, P.C. (1994). Evidence of linkage disequilibrium in the Spanish polycystic kidney disease 1 population. Am. J. Hum. Genet. 54, 899-908.

Peters, D. J. M., and Sandkuijl, L. A. (1992). Genetic heterogeneity of polycystic kidney disease in Europe. Contributions Nephrol. 97, 128-139.

Peters, D. J. M., Spruit, L., Saris, J. J., Ravine, D., Sandkuijl, L. A., Fossdal, R., Boersma, J., van Eijk, R., Nфrby, S., Constantinou-Deltas, C. D., Pierides, A., Brissenden, J. E., Frants, R. R., van Ommen, G.J. B., and Breuning, M. H. (1993). Chromosome 4 localization of a second gene for autosomal dominant polycystic kidney disease. Nature Genet. 5, 359-362.

Pound, S. E., Carothers, A. D., Pignatelli, P. M., Macnicol, A. M., 
Watson, M. L., and Wright, A. F. (1992). Evidence for linkage disequilibrium between $D 16594$ and the adult onset polycystic kidney disease (PKD1) gene. J. Med. Genet. 29, 247-248.

Ravine, D., Walker, R. G., Gibson, R. N., Sheffield, L. J., KincaidSmith, P., and Danks, D. M. (1991). Treatable complications in undiagnosed cases of autosomal dominant polycystic kidney disease. Lancet 337, 127-129.

Ravine, D., Walker, R. G., Gibson, R. N., Forrest, S. M., Richards, R. I., Friend, K., Sheffield, L. J., Kincaid-Smith, P., and Danks, D. M. (1992). Phenotype and genotype heterogeneity in autosomal dominant polycystic kidney disease. Lancet 340, 1330-1333.

Reeders, S. T. (1992). Multilocus polycystic disease. Nature Genet. 1, 235-237.

Reeders, S. T., Breuning, M. H., Davies, K. E., Nicholls, R. D., Jarman, A. P., Higgs, D. R., Pearson, P. L., and Weatherall, D. J. (1985). A highly polymorphic DNA marker linked to adult polycystic kidney disease on chromosome 16. Nature 317, 542-544.

Reeders, S. T., Keith, T., Green, P., Germino, G. G., Barton, N. J., Lehmann, O. J., Brown, V. A., Phipps, P., Morgan, J., Bear, J. C., and Parfrey, P. (1988). Regional localization of the autosomal dominant polycystic kidney disease locus. Genomics 3, 150-155.

Romeo, G., Costa, G., Catizone, L., Germino, G. G., Weatherall, D. J., Devoto, M., Roncuzzi, L., Zucchelli, P., Keith, T., and Reeders, S. T. (1988). A second genetic locus for autosomal dominant polycystic kidney disease. Lancet $i i, 8-10$.

Royle, N. J., Armour, J. A. L., Webb, M., Thomas, A., and Jeffreys, A. J. (1992). A hypervariable locus D16S309 located at the distal end of $16 p$. Nucl. Acids Res. $20,1164$.

Ryynanen, M., Dolata, M. M., Lampainen, E., and Reeders, S. T. (1987). Localisation of a mutation producing autosomal dominant polycystic kidney disease without renal failure. J. Med. Genet. 24, 462465.

Scheff, R. T., Zuckerman, G., Harter, H. Delmez, J., and Koehler, R. (1980). Diverticular disease in patients with chronic renal failure due to polycystic kidney disease. Ann. Int. Med. 92, 202-204.

Snarey, A., Thomas, S., Schneider, M. C., Pound, S. E., Barton, N. Wright, A. F., Harris, P. C., Reeders, S. T., and Frischauf, A.-M. (1994) Linkage disequilibrium in the region of the autosomal dominant polycystic kidney disease gene (PKD1). Am. J. Hum. Genet., in press.

Somlo, S., Wirth, B., Germino, G. G., Weinstat-Saslow, D., Giliespie, G. A. J., Himmelbauer, H., Steevens, L., Coucke, P., Willems, P., Bachner, L., Coto, E., Lopez-Larrea, C., Peral, B., San Millán, J. L., Saris, J. J., Breuning, M. H., Frischauf, A.-M., and Reeders, S.T. (1992). Fine genetic localization of the gene for autosomal dominant polycystic kidney disease (PKD1) with respect to physically mapped markers. Genomics 13, 152-158.

Thompson, A. D., Shen, Y., Holman, K., Sutherland, G. R., Callen, D. F., and Richards, R. I. (1992). Isolation and characterlzation of (AC) microsatellite genetic markers from human chromosome 16. Genomics 13, 402-408.

Wilson, P. D., and Sherwood, A. C. (1991). Tubulocystic epithelium. Kidney Int. 39, 450-463.

Wright, D. K., and Manos, M. M. (1990). Sample preparation from paraffin-embedded tissues. In PCR Protocols: A Guide to Methods and Applications, M. A. Innis, D. H. Gelfiand, J. J. Sniksky, and T. J. White, eds. (San Diego, California: Academic Press), pp. 153-166.

Zerres, K., Rudnik-Schöneborn, S., Deget, F., and German Working Group on Paediatric Nephrology (1993). Childhood onset autosomal dominant polycystic kidney disease in sibs: clinical picture and recurrence risk. J. Med. Genet. 30, 583-588.

\section{GenBank Accession Number}

The accession number for the sequence reported in this paper is L 33243. 